\title{
Trophoblasts, invasion, and microRNA
}

\section{Ludivine Doridot, Francisco Miralles, Sandrine Barbaux and Daniel Vaiman*}

Institut Cochin, INSERM U1016-CNRS UMR8104, Université Paris Descartes, Paris, France

\section{Edited by:}

Cees Oudejans, VU University

Medical Center, Netherlands

\section{Reviewed by:}

Jeffrey Mark Craig, Murdoch

Childrens Research Institute, Australia Carrie Ris-Stalpers, Academic Medical Center University of Amsterdam, Netherlands

Caroline Dunk, Lunenfeld Tanenbaum Research Institute, Mount Sinai

Hospital, Canada

\section{${ }^{*}$ Correspondence:}

Daniel Vaiman, Faculté de Médecine Hôpital Cochin, 24, rue du Faubourg St Jacques, 75014 Paris, France e-mail:daniel.vaiman@inserm.fr
MicroRNAs (miRNAs) have recently become essential actors in various fields of physiology and medicine, especially as easily accessible circulating biomarkers, or as modulators of cell differentiation. To this respect, terminal differentiation of trophoblasts (the characteristic cells of the placenta in Therian mammals) into syncytiotrophoblast, villous trophoblast, or extravillous trophoblast constitutes a good example of such a choice, where miRNAs have recently been shown to play an important role. The aim of this review is to provide a snapshot of what is known today in placentation mechanisms that are mediated by miRNA, under the angles of materno-fetal immune dialog regulation, trophoblast differentiation, and angiogenesis at the materno-fetal interface. Also, two aspects of regulation of these issues will be highlighted: the part played by oxygen concentration and the specific function of imprinted genes in the developing placenta.

Keywords: trophoblast, placental diseases, microRNAs, invasion mechanisms, angiogenesis, imprinted genes, oxygen, miR-210

\section{INTRODUCTION}

Mammalian pregnancy rests on a biological paradox: the intimate entangling of two different immunological systems during a long period of gestation (Medawar, 1961). In many species of mammals, the blastocyst enters the endometrial part of the uterus, during an invasive process occurring at the hatching of the blastocyst (4.5 days post coitum in mice, 7 days in humans). In humans, the external layer of the blastocyst (trophectoderm) proliferates, its outer cells syncytialize and lacunae form, defining digitations of the trophectoderm that form columns (primary chorionic villi). During the first trimester the existing structures persist and develop to form the floating villi of the placenta, while trophoblast cells that are not part of the villi form plugs sealing the intervillous space, and prevent maternal blood cells from being in contact with the syncytiotrophoblast (Carbillon et al., 2001). From the eighth and ongoing till at least the 16th week of gestation, the plugs begin to disappear, extravillous trophoblasts (EVTs) invade the uterine matrix, some going inside the decidua (interstitial trophoblasts), some fusing in a fashion similar to the syncytiotrophoblast (leading to placental bed giant cells), some replacing the maternal arteries endothelium in an ill-understood substitution process (endovascular trophoblasts), as depicted in Figure 1. The invasion of maternal tissue by trophoblast-derived cells is a specific and constant feature of human placentation (Goldman-Wohl and Yagel, 2002; Carter and Mess, 2007). Unsuccessful invasion is now recognized to lead to pregnancy diseases, such as preeclampsia (PE). $\mathrm{PE}$ is defined by a gestational hypertension accompanied by proteinuria that develops from the 20th week of gestation (Sibai, 2005). This disease has a prevalence estimated at $\sim 3-7 \%$, threatens the life of the mother and the fetus and its symptoms worsen from the appearance of the symptoms till the end of pregnancy. Delivery is the only real cure of this disease, which incidently is a major cause of iatrogenic prematurity. Genetic and epigenetic causes have been ascribed to PE (Chelbi and Vaiman, 2008).
The cells that compose these different structures derive from trophoblast stem cells, the fate of which has been particularly well-characterized in mice, and elegantly reviewed in Maltepe et al. (2010). This latter review emphasizes the involvement of epigenetic regulators in placental cell differentiation, such as DNA (cytosine-5)-methyltransferase 3-like (DNMT3L), various histone deacetylases (HDACs), suppressor of zeste 12 homolog (SUZ12). miRNAs are also important elements of the cell epigenetic machinery. Contrary to the other known players of epigenetic regulation, DNA methylation and post-translational histone modifications, they are able to affect gene expression after transcription by modulating mRNA stability and/or translation. The miRNAs achieve their epigenetic action by negatively modulating series of genes by targeting mRNA regulatory sequences often located in the $3^{\prime}$ untranslated sequence. Specifically, miRNAs are short (mean 22 nucleotides) ribonucleic acid (RNA) molecules. They are encoded by nuclear genes whose transcripts (called pri-miRNA) are processed in the nucleus to form pre-miRNAs through the action of the protein Drosha, or are part of introns that are also processed to form pre-miRNAs. Then, after export to the cytoplasm they are matured as miRNAs through the action of the protein Dicer through the RNA-induced silencing complex (RISC).

In the past 3 years, miRNAs have acquired a strong position in the list of factors influencing the different facets of trophoblast biology, such as proliferation, syncytialization, and invasion. A direct consequence, their impact on the major human placental diseases, such as PE, intra uterine growth restriction (IUGR, the failure of the fetus to reach a normal growth curve) or placenta accreta (a very severe obstetric disease where the placenta implants through the endometrium, and considerably increases the risk of hemorrhage at delivery) has also been revealed. A PubMed search for the keywords "miRNA" and "trophoblast" or "placenta," yields 137 results, the first paper having been published in 2006. One seminal study that set the de novo landscape 


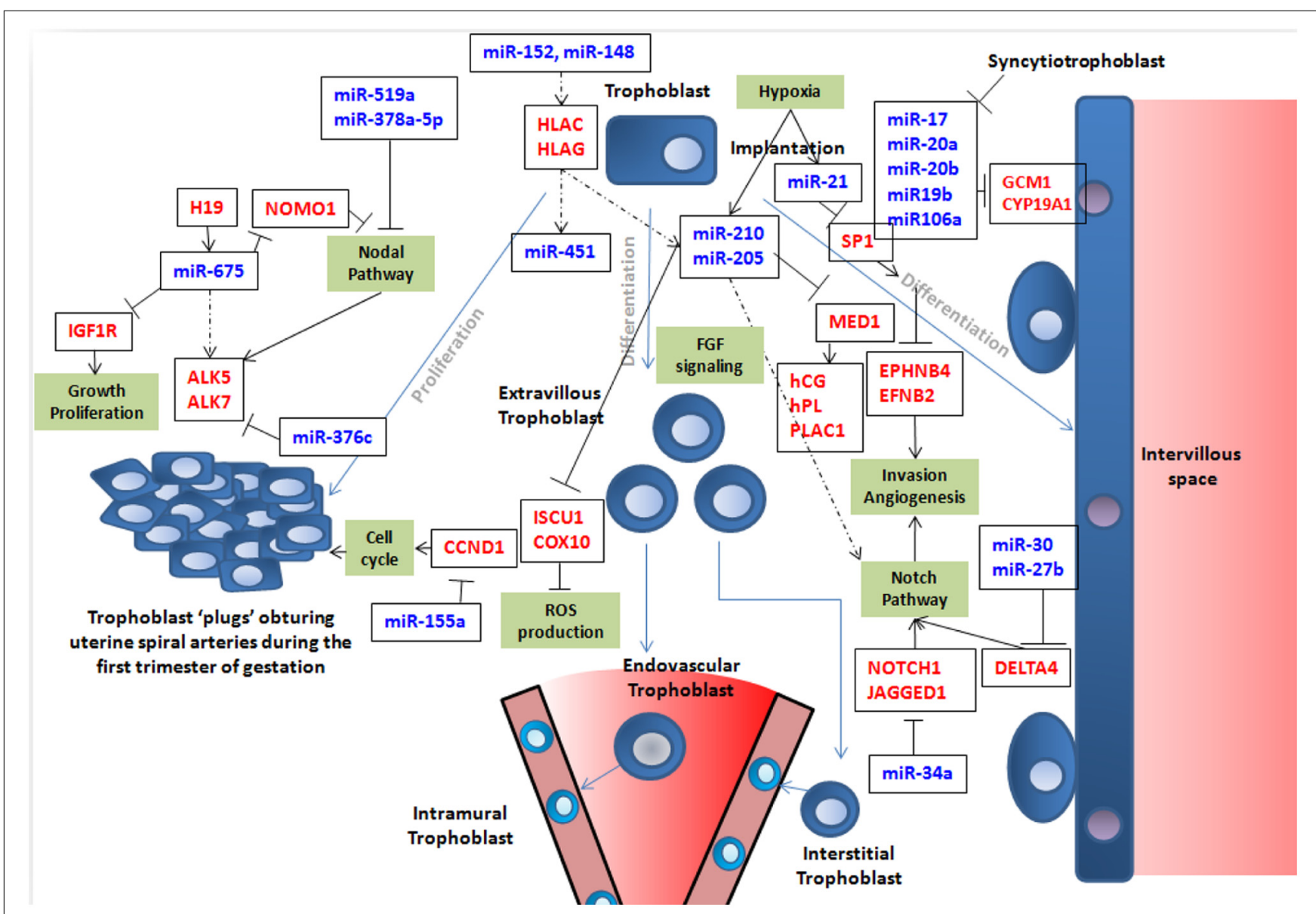

FIGURE 1 |This figure summarizes simplistically some of the features of trophoblast fate that are at least partly governed by miRNA expression. Trophoblast cells are represented in blue with a round nucleus. Trophoblasts (in blue) can proliferate (left part of the figure) or differentiate into syncytiotrophoblast (right part of the figure; in this case, nuclei are filled in purple) or into endovascular or interstitial trophoblast in the vascular context of maternal arteries (represented as a cone in the lower part of the figure; in this case the nuclei are represented in light blue). In this latter case, they eventually become enclosed into the arterial wall to become intramural trophoblast along pathways that are still debated as nicely described by Pijnenborg etal. (2006). In the figure, crucial genes for cell cycle, Nodal, Notch, and FGF pathways, ROS production, invasion, and angiogenesis are presented in red. Crucial miRNAs are in blue. Blue arrows represent cell differentiation/proliferation pathways. Black arrows symbolize induction. When black lines are terminated by an orthogonal bar they represent inhibition. In the cases where the relation is not fully demonstrated, dotted arrows are used. It is clear that this vision is far from exhaustive, but attempts to depict current knowledge on the role of miRNA in building placental structure and ensuring efficient vascularization of this organ. of miRNA-regulation in cells of the trophoblast lineage, was published in 2012 by Morales-Prieto et al. (2012). There, the authors screened 762 human miRNAs for their expression level in term and first trimester cytotrophoblasts, as well as in four cell lines: HTR8/SVneo (a cell line generated by transformation of an EVT), JEG-3 (a trophoblast-like line derived from a choriocarcinoma), $\mathrm{ACH}-3 \mathrm{P}$ and $\mathrm{AC} 1-\mathrm{M} 59$, the two latters consisting of choriocarcinoma fused either with early or late trophoblasts, respectively. One of the major outcomes of this work was the identification of clusters of placenta-specific miRNAs (C19MC, 54 miRNAs on chromosome 19, C14MC, 34 miRNAs on chromosome 14, and another minor cluster on chromosome 19). Their study also identified 27 miRNAs differentially expressed according to trophoblast age. Therefore this study gives an indicative encyclopedia of miRNAs susceptible to play an important role in the trophoblast.
In the present review, we will try to identify in the available literature the miRNAs that are known to be the major players of trophoblast function, in terms of (1) materno-fetal dialog leading to tolerance, (2) major differentiation events leading to syncytiotrophoblast generation from trophoblast cells, (3) angiogenesis and vasculogenesis in normal and pathological conditions, (4) impact of oxygen sensing, and (5) known links between miRNA and imprinted genes, since many of them are involved in placental function (Varrault et al., 2006; Renfree et al., 2013). We will mainly focus on those miRNAs for which validated gene targets have been identified. The orchestrator function of hypoxia in placental development will also be evoked. A limited number of miRNAs important for placental physiology are presented in Figure 1 and some of them are summarized in Table 1. The classical mechanisms of miRNA production and maturation, through the action of Drosha or Dicer for instance, are beyond the scope of 
Table 1 | Summary of some miRNAs discussed in the text and of their known function in placental physiology.

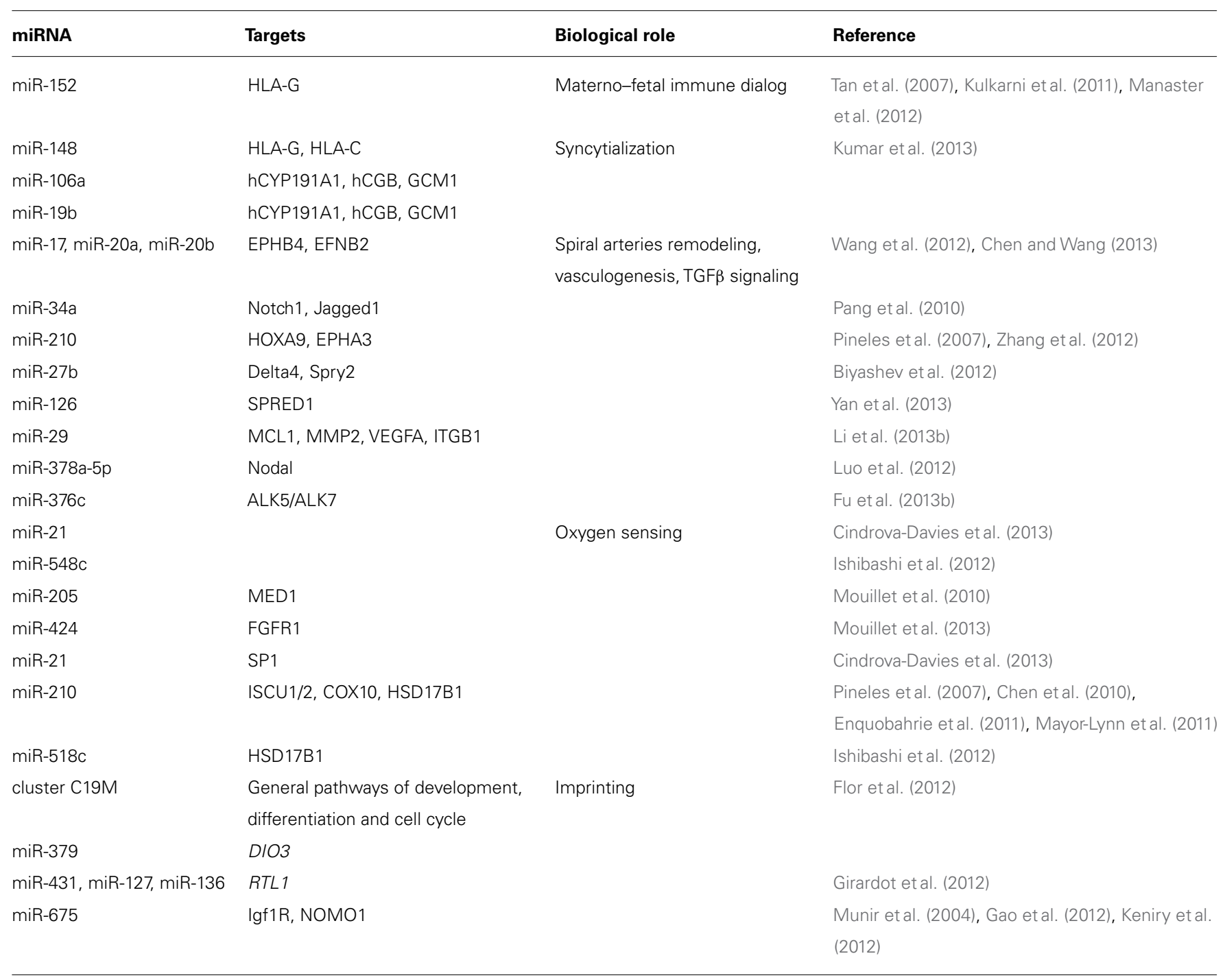

this review, although the description of the effects of Dicer inhibition on placental development will be mentioned. To obtain a clear vision of the mechanisms of miRNA maturation, the reader can consult the recent review from Chen and Wang (2013).

\section{miRNAs AND REGULATION OF THE MATERNO-FETAL IMMUNE DIALOG}

Implantation of the blastocyst occurs at $4.5 \mathrm{dpc}$ in mice and at 7 dpc in humans. At this stage, the blastocyst establishes a physical contact with the endometrium during the implantation window. Hatching of the blastocyst allows the primary immunological contact between the fetal antigens and the maternal immune system. The conundrum of fetal non-rejection has been underlined by Peter Medawar as early as in the 1950s (Billington, 2003). One element of the solution is provided by the fetal expression of a limited antigen repertoire, since contrary to most cells of the human body, trophoblasts do not express human leukocyte antigen (HLA)-A and $-\mathrm{B}$, the major histocompatibility (MHC) antigens that are highly polymorphic. Trophoblast cells express HLA-G (five alleles only; Hunt et al., 2006; one mRNA spliced in seven isoforms; Geraghty et al., 1987; Hunt et al., 2007) and HLA-C (two major alleles; Hiby et al., 2004; Moffett and Loke, 2006). Trophoblasts interact with uterine natural killer cells through their killer-cell immunoglobulin-like receptor (KIR) receptors (Hiby et al., 2010), two major forms of which exist (KIR-A and KIR-B). Some combinations of KIR and HLA-C have been shown to predispose to $\mathrm{PE}$, but overall, the system is tuned to allow tolerance. To note, in recent years, HLA-G has been considered as a general immune-tolerogenic molecule in various tissues (Wiendl et al., 2005; Carosella, 2011; Gonzalez et al., 2012). HLA-G is expressed by EVT, and its expression has been found regulated by $m i R-152$ in the context of asthma (Tan et al., 2007). More recently, Manaster et al. (2012) showed that in EVT, HLA-G mRNA is targeted as well by $m i R-148$, and this irrespectively to a specific single nucleotide 
polymorphism (SNP) located in the 3'-untranslated region (UTR) of HLA-G. This down-regulation is associated with an enhanced killing activity of natural killer (NK) cells. Very recently, it has been shown that in $\mathrm{CD} 4^{+} \mathrm{T}$ lymphocytes, soluble HLA-G modulates the expression of miRNA-451 and miRNA-210 (Morandi and Pistoia, 2013). These sets of results are extremely important in the context of human pregnancy. Among $\mathrm{CD} 4^{+} \mathrm{T}$ uterine lymphocytes, a small proportion $(\sim 5 \%)$ consists in Treg cells. These cells when maturated in peripheral organs, especially in uterine tissue, are key elements for a successful placentation in placental mammals (Samstein et al., 2012). HLA-C is also targeted by miRNAs, especially miR-148 (Kulkarni et al., 2011) although the impact of this regulation has mainly been studied in the context of HIV infection with the description of a sensibility-modulating SNP in the 3'-UTR of the gene. This regulation of HLA-C by miRNA has not been studied in the trophoblast context, nevertheless it is strongly expressed in cells of trophoblast origin (Manaster et al., 2012), suggesting that it may play a role in the expression of this antigen. To summarize, miRNAs appear as able to modulate very early the immunological balance of the uterine-embryo contact.

\section{miRNAs AND THE TROPHOBLAST-SYNCYTIOTROPHOBLAST TRANSITION}

Besides these very early effects on trophoblast biology, miRNAs have recently been shown to play extensive roles on the fate of trophoblasts. One of them is the evolution into syncytiotrophoblast. In fact near the end of pregnancy, villous trophoblasts become very rare, limiting the rejuvenation capability of the syncytiotrophoblast (Rigourd et al., 2009). Recently, Kumar et al. (2013) interrogated by microarray analysis the developmental transition leading to syncytiotrophoblast differentiation. In this study, the authors identified miRNAs belonging to three clusters modified during trophoblast differentiation ( $m i R-17,20 a, 20 b, 19 b$ belonging to the miR-17 92 cluster, on chromosome 13q31; miR-106a, on chromosome $\mathrm{X}$, belonging to cluster 106a $\sim 363$, and $\mathrm{miR}$ 93 , on chromosome 7 , belonging to the $\mathrm{miR} 106 \mathrm{~b} \sim 25$ cluster). These miRNAs are all down-regulated in syncytiotrophoblast. $m i R-106 a$ and $m i R-19 b$ directly target the 3 '-UTR of the aromatase ( $h C Y P 19 A 1)$ gene. Aromatase is expressed in the syncytiotrophoblast exclusively. One of the most interesting targets discovered by the authors is glial cell missing homolog1 (GCM1), a transcription factor playing a major function in trophoblast differentiation and fusion (Anson-Cartwright etal., 2000), also known to be down-regulated in PE, one of the most important diseases of pregnancy (Chen et al., 2004; Chiang et al., 2009; Drewlo et al., 2011; Wilson et al., 2011). GCM1 expression is also reduced fourfold in JEG-3 cells overexpressing STOX1 that share strong transcriptomic characteristics with the human preeclamptic placenta (Rigourd et al., 2008, 2009). Interestingly, one of the most classical markers of syncytialization, human chorionic gonadotrophin (hCG $\beta$ ), was also decreased by miR-19b and miR106a; in the absence of predicted bona fide target in the gene, it was shown that this results from an indirect action of GCM1 (Kumar et al., 2013). In the same study the authors show that c-Myc binds directly to the 5' upstream region of the clusters miR-17 92 and miR$106 \mathrm{a} \sim 363$, the expression of this protooncogene being decreased during syncytiotrophoblast differentiation. These novel mechanistic data especially on the miR-17 92 and miR-106a 363 clusters, strengthen recent observations published by Wang et al. (2012) that show up-regulation of miR-17, miR-20a (belonging to miR-17 92) and $m i R-20 b$ (belonging to miR-106a 363) in preeclamptic placentas, which as mentioned in the introduction is a disease generally caused by trophoblast dysfunction and presumably associated to a generalized activation of the endothelium.

\section{miRNAs, ANGIOGENESIS, AND VASCULOGENESIS AT THE UTERO-PLACENTAL INTERFACE: REGULATION OF THE NOTCH PATHWAY AND LINKS WITH PREECLAMPSIA}

A key event in early placentation involves the remodeling of the uterine spiral arteries by migrating EVTs a process known as pseudovasculogenesis or vascular mimicry (Ji et al., 2013). This process transforms the uterine spiral arteries from high resistance, low flow muscular vessels to low resistance, and high flow vessels enabling them to ensure proper irrigation to the developing placenta/fetus. It has been consistently reported that in early onset PEs (generally the most severe) the remodeling of the spiral arteries is impaired (Red-Horse et al., 2004). This leads to reduced perfusion of the developing placenta, subsequent intermittent hypoxia-reoxygenation episodes, reactive oxygen (ROS) production, cell injury, inflammation, and liberation of placental factors and debris into the maternal circulation. Spiral artery remodeling appears to be a multi-stage process involving: spiral arteries preliminary remodeling (characterized by vacuolization and apoptosis of resident ECs), EVTs migration and invasion of the decidua and myometrium, incorporation of EVTs into the spiral arteries vessel walls, and acquisition by the endovascular EVTs of an EC-like phenotype. The trans-differentiation of EVTs into EC-like cells (vascular mimicry) results in the down-regulation of epithelial cell-type markers E-cadherin and integrin $\alpha 6 \beta 4$ and the induction of the expression of endothelial adhesion molecules such VE-cadherin, PECAM, NCAM as well as integrins $\alpha 5 \beta 1$, $\alpha 1 \beta 1, \alpha \mathrm{V} \beta 3$ (Damsky and Fisher, 1998).

Experimental evidence of the implication of miRNAs in the different stages of spiral arteries remodeling and their eventual dysfunction in PE is still limited. A recently published study reports an increased expression of members of the miR-17 family miRNAs (miR-17, miR-20a, and miR-20b) in PE versus normotensive human placentas (Wang et al., 2012). Among the potential targets of the miR-17 family miRNAs the authors identified the ephrin receptor B4 (EPHB4) and ephrin B2 (EFNB2), two Eph receptor tyrosine kinases involved in angiogenesis (Wang et al., 1998). In the placenta, the couple EFNB2/EPHB4 directs EVTs invasion away from the placenta and towards uterine spiral arterioles (Red-Horse et al., 2005). The same authors found that the forced expression of miR-20a in BeWo cells (a human cell line derived from a placental choriocarcinoma) inhibits syncytialization and induces the expression of ECs markers. Therefore, it has been postulated that in normal placentation low levels of miR-17 family miRNAs allow a higher expression of EFNB2/EPHB4 in the EVTs facilitating the invasion and uterine spiral arteries remodeling. Ephrin receptors B2 and B4 are receptor tyrosine kinases and several reports suggest their involvement in cell differentiation mechanisms (Adams, 
2002). They are also involved in vascular endothelial growth factor (VEGF)-mediated angiogenic functions through regulation of signaling of the VEGFR2 and VEGFR3 receptors in endothelial cells (Sawamiphak et al., 2010; Wang et al., 2010). In PE, an increased expression of miR-17 family members would suppress the expression of EFNB2/EPHB4 resulting in inhibition of spiral arteries invasion and endovascular EVTs differentiation (Chen and Wang, 2013).

Recent studies have implicated the Notch pathway in the process of spiral arteries remodeling and in the pathogenesis of PE (Hunkapiller etal., 2011). This is in good accordance with the known role of Notch signaling in vascular patterning and in the specification of arterial identity (Roca and Adams, 2007; Swift and Weinstein, 2009). The core component of this pathway consists of four transmembrane receptors (Notch1-4) and five ligands (Delta1/3/4 and Jagged 1/2) that are dynamically expressed through placental development (Hunkapiller et al., 2011). Conditional deletion of Notch2 in mice leads to significant reduction in placental perfusion and arterial invasion by trophoblasts (Gasperowicz and Otto, 2008). Also, when human cytotrophoblasts are grown on Matrigel, NOTCH promotes their invasion and acquisition of an arterial EC-like phenotype marked by EFNB2 up-regulation (Gasperowicz and Otto, 2008). Moreover, significant JAGGED1 down-regulation in the perivascular and endovascular EVTs has been detected in PE, and found to be associated with failed vascular remodeling (Gasperowicz and Otto, 2008). Interestingly, overexpression of $m i R-34 a$ in the choriocarcinoma cell line JAR (derived from a trophoblastic tumor of the placenta) inhibits cell invasion by targeting Notch1 and Jagged1 (Pang et al., 2010). This suggests a possible role of miRNAs in the regulation of Notch signaling in the early stages of uterine invasion and spiral arteries remodeling. Recently, we have shown that while pri-miR-34a is overexpressed twice in preeclamptic placentas (where the gene promoter is demethylated), the mature miR-34a is present at a much lower level in pathological placentas than in normal placentas (Doridot et al., 2013). Our data suggest that this mechanism could contribute to an indirect up-regulation of SERPINA3 in pathological pregnancies (Chelbi et al., 2007, 2012), this gene being an important actor of placental homeostasis and trophoblast invasion.

Many other miRNAs are known to be involved in the regulation of Notch signaling. Among these, miR-30 targets DLL4 (delta like ligand-4; Bridge et al., 2012), and miR-210 over-expression in ECs causes up-regulation of Notch1 and induces migration and tube formation in Matrigel (Lou et al., 2012). Interestingly, miR-210 is known to be one of the most up-regulated miRNAs in the preeclamptic placenta and has been involved in trophoblast migration and invasion process (Pineles et al., 2007; Zhang et al., 2012). Another recent study has shown that $m i R-27 b$ controls two critical vascular functions in zebrafish: it turns on the angiogenic switch by promoting endothelial tip cell fate and sprouting and it promotes venous differentiation. The Notch ligand Delta4 and Sprouty homolog 2 (Spry2) were identified as miR-27b targets involved in these functions. Moreover, miR-27b is necessary for the formation of the first embryonic vein in fish and controls the expression of arterial and venous markers in human endothelium, including EFNB2, EPHB4, fms-related tyrosine kinase 1
(Flt1), and fms-related tyrosine kinase 4 (Flt4; Biyashev et al., 2012). Also, in vascular smooth muscle cells (VSMCs) Notch signaling through Jagged1 promotes a differentiated phenotype characterized by an increased expression of contractile proteins, this effect being mediated through the induction of miR-143/145 transcription (Boucher et al., 2011). Finally, several miRNAs (miR9, miR-21, miR-27, miR-124, miR-130, miR-148, and miR-181) involved in vascular development and ECs signaling have been predicted to target components of the Notch pathway (Anand, 2013). Therefore, miRNAs regulation of Notch signaling might play an important role in placental angiogenesis.

In a larger context, the importance of miRNAs in angiogenesis and ECs physiology has been established by the study of Dicer inactivation. Thus, Dicer hypomorphic mice present severely impaired vascular development in both the embryo and yolk sac (Yang et al., 2005). Endothelial specific deletion of Dicer in mice decreases postnatal angiogenesis (Suarez et al., 2008). Also, VSMCs inducible deletion of Dicer in mice, leads to impaired differentiation, contractility, and vascular remodeling (Albinsson et al., 2011). Altogether, these studies point out to the essential role of Dicer and hence of miRNAs for the proper development and function of vascular cells. The analysis of the miRNAs expressed in HUVECs has allowed identifying miRNAs involved in ECs function (Poliseno et al., 2006). Among these miR-126 has been found as one of the most abundantly expressed in ECs (Fish et al., 2008; Wang et al., 2008). This miRNA is essential for angiogenesis and targets Sprouty related EVH domain containing protein 1 (SPRED1), a negative regulator of vascular endothelial growth factor 1 (VEGF). Owing to its role in endothelial progenitor cells (EPCs) physiology, a recent study has suggested that miR-126 is essential for placental vasculogenesis and suggested that it could provide a therapeutic approach for PE (Yan et al., 2013). Another study has shown that $m i R-29$ induces apoptosis and inhibits the invasive and angiogenic capacities of trophoblast cell lines (HTR8/SVneo, BeWo, and JAR). This study has shown that miR-29b regulates the expression of myeloid cell leukemia sequence 1 (MCL1), matrix metalloproteinase 2 (MMP2), vascular endothelial growth factor A (VEGFA), and integrin $\beta 1$ (ITGB1) genes by directly binding their 3'-UTRs. Moreover, an inverse correlation was detected between miR-29b and the expression levels of these targets genes in PE (Li et al., 2013b).

In conclusion, to date many miRNAs have been found to play important roles in the regulation of angiogenesis and ECs homeostasis (Hartmann and Thum, 2011; Small and Olson, 2011), an issue indirectly linked to trophoblast differentiation. Indeed, oxygen availability or scarceness are landmark morphogens for trophoblast cell fate.

Despite an increasing number of studies seeking to identify miRNAs involved in the pathogenesis of PE, only a few of them have been associated to the essential process of placental angiogenesis, and in particular to its earliest steps (Fu et al., 2013a). In humans, the analysis of the role of miRNAs in spiral arteries remodeling is complicated due to the difficulty to access to placental tissue for experimental purposes. Therefore, it is likely that further studies will be greatly dependent on animal models (i.e., mice), but also, owing to the particularities of human placentation, on the development of in vitro models able to reproduce the 
different stages and cellular interactions (cell contacts, cytokines signaling, miRNA exchanges mediated by exosomes, etc.) which are likely involved in spiral artery transformation.

\section{miRNAs AND OXYGEN SENSING AT THE TROPHOBLAST LEVEL}

Hypoxia is a key signal for normal placental development in physiological pregnancy, and has a crucial role in the control of trophoblast differentiation into invasive or proliferating cells (Zhou etal., 1997; Jauniaux etal., 2003). Heretofore, its effect was primarily described as mediated through HIF transcription factors, but recently, it was recognized that miRNAs induced by hypoxia could participate by regulating genes that are not directly hypoxia-inducible (Huang et al., 2009). Hypoxia-inducible miRNAs constitute a new group of genes that could be important for trophoblast differentiation. To identify such miRNAs, trophoblast cells purified from term placentas were grown in normoxia or hypoxia $\left(48 \mathrm{~h}, 1 \% \mathrm{O}_{2}\right.$ ), and miRNAs expression profile was studied by microarray and Northern blot (Mouillet et al., 2010). Among the most highly expressed miRNAs, seven miRNAs were shown modified in hypoxia: $m i R-93, m i R-205, m i R-224, m i R-335, m i R-$ 424, $m i R-451$, and $m i R-491$. Other miRNAs induced by hypoxia were identified by targeted approaches, as they were shown to be modified in preeclamptic placentas (considered as hypoxic) or pregnancies associated with abnormal placental Doppler waveforms, indicative of a blood circulation defect; this was the case for miR-21 (Cindrova-Davies et al., 2013), miR-210 (Ishibashi et al., 2012; Lee et al., 2012; Muralimanoharan et al., 2012), and miR$518 c$ (Ishibashi et al., 2012). These hypoxia-induced modifications in miRNA content are probably not linked to miRNAs biogenesis, since the responsible enzymes are apparently not modified by hypoxia (Donker et al., 2007).

For some of these candidate miRNAs, their potential involvement in trophoblast function and/or differentiation was assessed thanks to the identification of their target genes. miR-205 concentration is increased in hypoxic conditions (around twice after $48 \mathrm{~h}$ at $<1 \% \mathrm{O}_{2}$ ) in primary trophoblast cells and miR-205 targets MED1, as validated by luciferase assay (Mouillet et al., 2010). MED1 is an important regulator of murine placental development (Landles et al., 2003), that regulates the expression of hCG, human placental lactogen (hPL), and placental-specific protein 1 (Plac1) in primary trophoblast cells (Mouillet et al., 2010). miR424 is down-regulated around fivefold following $72 \mathrm{~h}$ of hypoxia in primary trophoblast cells (but not in the trophoblast cell line JEG-3). It targets FGFR1 as demonstrated by luciferase assay (Mouillet et al., 2013). FGF signaling has been implicated throughout development in many signaling pathways controlling cellular proliferation, differentiation, survival, and angiogenesis (Turner et al., 2010). FGFR1 role in pregnancy is however unclear, since its deletion in mice is embryonically lethal around E7.5-E9.5, preventing a detailed analysis of its role in the placenta (Deng et al., 1994; Yamaguchi et al., 1994). miR-424 amounts are also restricted by other signals inhibiting differentiation (in syncytiotrophoblast cells), such as dimethyl sulfoxide (Mouillet et al., 2013). In the same article, $m i R-503$, localized near miR-424 on chromosome X, was shown to exhibit the same expression profile in primary trophoblast cells, suggesting the existence of a polycistronic precursor containing both miRNAs. miR-21 is elevated in placentas with abnormal Doppler waveforms (IUGR or preeclamptic) compared to control or preeclamptic placentas with normal Doppler waveforms (around twice; Cindrova-Davies et al., 2013). Furthermore, in placental explant submitted to $3 \mathrm{~h}$ of hypoxia $\left(0.5 \% \mathrm{O}_{2}\right)$ followed by $20 \mathrm{~h}$ at $10 \% \mathrm{O}_{2}$ in order to mimic hypoxia/reoxygenation injury, there is an up-regulation of miR-21 (1.6-fold). This miRNA was shown to directly target SP1, which in turn controls the expression of cystathionine- $\gamma$-lyase (CSE), responsible for hydrogen sulfide $\left(\mathrm{H}_{2} \mathrm{~S}\right)$ synthesis (Yang et al., 2012). Yet $\mathrm{H}_{2} \mathrm{~S}$ is thought to have a vasodilator effect, which could be important for a correct placentation. This is substantiated by the decreased expression of CSE in placentas with abnormal Doppler waveforms, and in the placental explant submitted to hypoxia/reoxygenation injury (Wang et al., 2013b). To note, SP1 a zinc finger transcription factor is recurrently found important in placental physiology modulation (Gascoin-Lachambre et al., 2010; Chelbi et al., 2012; Vaiman et al., 2013). miR-21 could have other effects on trophoblast function in terms of proliferation, since it has been described as a pro-invasive oncogene in breast cancer (Xu et al., 2008). miR-210 is probably the miRNA for which there is the most abundant literature in relation with placental hypoxia. Actually, it was one of the first identified hypoxia-up-regulated miRNAs, principally in the context of tumors (Kulshreshtha et al., 2007). Since then, miR-210 was shown to be induced by hypoxia in a vast number of cell types (Hsu et al., 2012), leading to rename it "hypoxamiR." miR-210 was also found affected in every miRNA screen comparing preeclamptic and normal placentas (Pineles et al., 2007; Santner-Nanan et al., 2009; Enquobahrie et al., 2011; Mayor-Lynn et al., 2011). miR210 targets notably iron sulfur cluster scaffold proteins (ISCU1/2; Chan etal., 2009; Chen etal., 2010) and cytochrome c oxidase assembly protein (COX10; Chen et al., 2010). ISCU1/2 facilitate the assembly of iron-sulfur clusters, prosthetic groups that are critical for electron transport and mitochondrial oxidation-reduction reactions, while COX10 is essential for the assembly of electron transport system complexes I and IV showing how miR-210 may strongly impact mitochondrial function. Colleoni et al. (2013) confirmed recently that such mitochondrial alterations occur in trophoblast cells by cultivating JEG-3 cells for 4 days in hypoxia $\left(1 \% \mathrm{O}_{2}\right)$ and using high altitude placentas, in which miR-210 is around twice higher than in sea-level placentas, demonstrating a diminished protein level for complexes I and IV. Mitochondrial function following miR-210 induction by hypoxia was also assessed in preeclamptic placentas and primary trophoblast cells isolated from control placentas (Muralimanoharan et al., 2012). In this latter study, the authors demonstrated mitochondrial dysfunction in placentas from pregnancies complicated by PE, associated with elevated ROS production and HIF-1 $\alpha$ stabilization, up-regulation of miR-210 and down-regulation of ISCU. They demonstrated that increased miR-210 is necessary and sufficient for explaining the observed mitochondrial dysfunction, by using gain of function and loss of function approaches. miR210 effect on iron metabolism could also impact the invasive capacity of trophoblast as suggested by a decreased invasion of human first-trimester trophoblast cells in Matrigel ${ }^{\mathrm{TM}}$ following ISCU knock-down (Lee et al., 2011). However the invasive defect following miR-210 expression can also be due to other validated 
targets such as EphrinA3 and HOXA9, both involved in migration and vascular remodeling (Zhang et al., 2012). In this latter study, the authors also demonstrated that miR-210 expression is also regulated by NF- $\kappa \mathrm{B}$ (p50 subunit), in addition to HIF1 $\alpha$. MiR-210 also targets hydroxysteroid (17- $\beta$ ) dehydrogenase 1 (HSD17B1), a steroidogenic enzyme gene predominantly expressed in the placenta, the encoded protein catalyzing the conversion of estrone to 17- $\beta$ estradiol (Ishibashi et al., 2012). This gene is also the target of $m i R-518 c$, another miRNA expressed in the syncytiotrophoblast layer of the placenta. These two miRNAs were found by comparing miRNA profile from normal and preeclamptic placentas, by high throughput sequencing and qPCR. Luciferase assays confirmed HSD17B1 as a genuine target of miR-210. miR-518c and miR-210 were then assessed in JEG-3 and BeWo cells exposed to hypoxia $\left(1 \% \mathrm{O}_{2}\right)$ and demonstrated to be induced. This study led to propose to use HSD17B1 as a biomarker, as it was shown reduced in the plasma from preeclamptic patients, before the onset of the symptoms. However, how the reduced HSD17B1 could participate to the physiopathology remains unclear.

For most identified hypoxia-up-regulated miRNAs in trophoblast cells, there are neither identified specific target genes, nor explanations about a possible involvement in trophoblast cell function. However, description of some targets found in other cell type can lead to interesting hypotheses. For example, overexpression of miR-93 attenuated hypoxia-induced apoptosis in endothelial and skeletal muscle cells, enhanced proliferation in both cell types, and enhanced endothelial cell tube formation (Hazarika et al., 2013). $m i R-224$ was recently shown to target Raf kinase inhibitor protein (RKIP), a tumor suppressor that protects against metastasis and genomic instability, and to have a positive effect on Transwell migration, 3D growth in Matrigel, and wound healing in breast cancer cell lines, probably through RKIP target genes, notably MMP1 (Huang et al., 2012). miR-335 overexpression can simultaneously suppress the invasiveness of ovarian cancer cells and lung cancer cells and promote apoptosis of lung cancer cells by targeting Bcl-w (Cao et al., 2013; Wang et al., 2013a). miR-451 inhibits cell proliferation in human hepatocellular carcinoma through direct suppression of IKK- $\beta$ (via the down-regulation of cyclin D1 and cMyc; Li et al., 2013a). Finally, miR-491 is involved in the migratory capacity of hepatocellular carcinoma cells by inhibition of matrix metalloproteinases (Yu et al., 2013). In conclusion, all these recent studies involve hypoxia-up-regulated trophoblast miRNAs in the control of proliferation, migration, or invasion, all key processes in trophoblast function. Given the pivotal role of oxygen, playing on this factor on purified trophoblast, before or after syncytialization could help characterizing exhaustively the miRNAs involved and shed a novel light on the pathways of trophoblast differentiation in physiology and pathology.

\section{miRNAs AND REGULATION OF IMPRINTED GENES IN TROPHOBLAST AND PLACENTAL BIOLOGY}

The chromosome 19 miRNA cluster that we mentioned in the introduction (C19MC) is hosted in a $100-\mathrm{kb}$ region located on human chromosome 19q13 and contains 46 tandemly repeated miRNAs (Bortolin-Cavaille et al., 2009). The cluster is submitted to parental imprinting, resulting in the expression of the primary long transcript exclusively from the paternal copy, from which introns containing the different miRNAs are spliced (Bortolin-Cavaille et al., 2009; Noguer-Dance et al., 2010). This regulation is under the control of a $\mathrm{CpG}$ rich region that undergoes an extensive methylation only in the maternal gametogenesis, resulting in the establishment of a differentially methylated region (DMR) upstream the cluster. Other imprinted genes are located in the neighborhood of this cluster, including PEG3 and ZNF331. These C19MC miRNAs are specific of the primate lineage and are expressed almost exclusively in embryonic stem cells and the placenta (Noguer-Dance et al., 2010).

Expression of the C19MC miRNAs can be detected in trophoblastic cells but also in stromal cells where $m i R-520 c-3 p$, miR519a-3p, and miR517a-3p are expressed, whatever the gestational age (Flor et al., 2012). Trophoblastic model cell lines such as JEG and BeWo seem to express them whereas HTR8 cells mimicking EVTs do not. Some differences can also be observed depending on the differentiation stage of the cells. The presence of these miRNAs could also be observed within exosomes, vesicles that are secreted by the syncytiotrophoblast layer, released in the fetomaternal circulation and that are likely to participate to exchanges between the fetus via its placenta, and the mother (Donker et al., 2012). An abnormal expression of these miRNAs is observed in some cancers, suggesting an oncogenic function and giving clues concerning their possible physiological function. For example the overexpression of a C19MC miRNA, miR-519d, in hepatic cancers is associated with an increased proliferation and invasion, by direct targeting of molecules regulating the cell cycle such as $p 21$, PTEN, AKT3, and TIMP2 (Fornari et al., 2012). In the developing placenta, C19MC miRNAs could participate to the trophoblastic proliferation necessary to constitute a large placenta required in primates and to the deep invasion of the maternal decidua necessary to establish a correct blood flow to fulfill fetal needs. If direct interactions between the C19MC miRNAs and proved targets have not been extensively described, predicted targets indeed belong to general pathways of development, differentiation and cell cycle. Within the cluster, seed sequences are mostly shared by the different genes (Lin et al., 2010). miR520c-3p seems to be the only one of the cluster responding positively to hypoxia.

Located within a large imprinted domain on chromosome 14q32, the C14MC cluster contains 53 miRNAs tandemly repeated in two segments overlapping about $40 \mathrm{~kb}$. The region also shelters the MEG3, DLK1, RTL1, and DIO3 imprinted coding genes (Morales-Prieto et al., 2012). The C14MC miRNAs are expressed only from the maternal allele as $M E G 3$ whereas their neighbor coding genes DIO3, RTL1, and DLK1 are paternally expressed, all under the control of a specific upstream DMR. This profile is conserved in the mouse genome and the cluster appears to be eutherian-specific. Some C14MC miRNAs directly target the nearby imprinted genes DIO3 ( $m i R-379$ ), RTL1 ( $m i R-431, m i R-127, m i R-136)$, suggesting a role in placental development (Girardot et al., 2012). Indeed, mice null for Rtl1 or overexpressing it display an abnormal development and anomalies of the placenta, notably in capillary formation (Sekita et al., 2008). Their expression seems to be concentrated in the developing embryo and placenta. Their predicted targets and expression profiles could propose a role in stem cell physiology and pluripotency. 
The IGF2-H19 locus is a well-deciphered imprinted locus located on human chromosome $11 \mathrm{p} 15$ and murine chromosome 7. While the IGF2 gene codes for the insulin-like growth factor 2, H19 is a large non-coding RNA. Both genes are epigenetically regulated under the control of a main imprinting control region (ICR) and in opposite ways: IGF2 is expressed from the paternal allele while $H 19$ is maternally expressed. If the function of IGF2 as a fetal and placental growth-promoting factor is well known, the mechanisms of action of $\mathrm{H} 19$ remain less clear. A tumor-suppressive effect has been observed in mice in a model of colorectal cancer (Yoshimizu et al., 2008). In particular, $2 \mathrm{miR}$ NAs $m i R-675-5 p$ and $m i R-675-3 p$, are produced from the first exon of $\mathrm{H} 19$, the region showing the highest conservation within mammals. Though H19 is widely expressed in various fetal tissues, miR-675 is only abundant and increasingly expressed in placental tissues, in the labyrinthe from E11,5. The maturation of miR-675 seems to be blocked in the first part of gestation by the binding of the HuR protein (Keniry et al., 2012). There is an inverse correlation between the decrease of $\mathrm{HuR}$ and the increase of miR-675 expression, together with the slowing or arrest of placental growth during gestation time. In particular, Igf1R, the main receptor of Igf2, is a target of miR-675. The authors hypothesized that miR-675 plays a role in controlling placental growth and size along gestation and that $\mathrm{H} 19$ serves as a reservoir of miR675 , produced in response to stress or particular needs during gestation (Keniry et al., 2012). Nodal modulator1 (NOMO1) is a direct demonstrated target of miR-675 (Gao et al., 2012). Downregulation of H19/miR-675 and increased expression of NOMO1 are observed in preeclamptic placentas. NOMO1 participates to the Nodal signaling pathway involved in trophoblast proliferation control and apoptosis (Munir et al., 2004). H19 inhibition in JAR cells resulted in the abolition of apoptosis and proliferation (Yu et al., 2013). Besides the involvement of imprinted genes in Nodal modulation it is worth mentioning the important recent findings of Luo and co-workers, that after identifying a potential binding site for miR-378a-5p in the 3' UTR of Nodal, demonstrated this targeting. Functionally speaking, the authors showed that overexpression of the pre-miR (miR-378) induces several enhancements of trophoblast function in HTR8 cells (cell survival, proliferation, migration, invasion) and outgrowth and spreading of EVT from first trimester placental explants (Luo et al., 2012). Similarly, the same team showed that $m i R-376 c$ targets ALK5 and ALK7 (receptors for transforming growth factor- $\beta$ and Nodal, respectively), its overexpression leading to improved trophoblast "behavior" as that of miR-378a-5p (Fu et al., 2013b). It is interesting to notice that miR-378a-5p is reduced in PE. Overall, these results emphasize the role of Nodal signaling in trophoblast function.

\section{CONCLUSIONS}

The number of articles published on miRNA and trophoblast development has been steadily increasing every year since 2006, to reach 37 in 2012, and 33 in July 2013 when this review has been written. This increase clearly illustrates the impact of miRNAs in placental physiology and pathology. The present review is clearly not exhaustive, mainly because of space restriction. It nevertheless gives an overview of several of the major aspects where miRNAs play a physiological role in placental development and trophoblast differentiation. In this context, the links between imprinted genes, oxygen signaling, proliferation, angiogenesis, and invasion in connection with miRNA expression will likely be better understood in the future.

\section{REFERENCES}

Adams, R. H. (2002). Vascular patterning by Eph receptor tyrosine kinases and ephrins. Semin. Cell Dev. Biol. 13, 55-60. doi: 10.1006/scdb.2001.0289

Albinsson, S., Skoura, A., Yu, J., DiLorenzo, A., Fernandez-Hernando, C., Offermanns, S., etal. (2011). Smooth muscle miRNAs are critical for post-natal regulation of blood pressure and vascular function. PLOS ONE 6:e18869. doi: 10.1371/journal.pone.0018869

Anand, S. (2013). A brief primer on microRNAs and their roles in angiogenesis. Vasc. Cell 5, 2. doi: 10.1186/2045-824X-5-2

Anson-Cartwright, L., Dawson, K., Holmyard, D., Fisher, S. J., Lazzarini, R. A., and Cross, J. C. (2000). The glial cells missing-1 protein is essential for branching morphogenesis in the chorioallantoic placenta. Nat. Genet. 25, 311-314. doi: $10.1038 / 77076$

Billington, W. D. (2003). The immunological problem of pregnancy: 50 years with the hope of progress. A tribute to Peter Medawar. J. Reprod. Immunol. 60, 1-11. doi: 10.1016/S0165-0378(03)00083-4

Biyashev, D., Veliceasa, D., Topczewski, J., Topczewska, J. M., Mizgirev, I., Vinokour, E., et al. (2012). miR-27b controls venous specification and tip cell fate. Blood 119, 2679-2687. doi: 10.1182/blood-2011-07-370635

Bortolin-Cavaille, M. L., Dance, M., Weber, M., and Cavaille, J. (2009). C19MC microRNAs are processed from introns of large Pol-II, non-protein-coding transcripts. Nucleic Acids Res. 37, 3464-3473. doi: 10.1093/nar/gkp205

Boucher, J. M., Peterson, S. M., Urs, S., Zhang, C., and Liaw, L. (2011). The miR-143/145 cluster is a novel transcriptional target of Jagged-1/Notch signaling in vascular smooth muscle cells. J. Biol. Chem. 286, 28312-28321. doi: 10.1074/jbc.M111.221945

Bridge, G., Monteiro, R., Henderson, S., Emuss, V., Lagos, D., Georgopoulou, D., et al. (2012). The microRNA-30 family targets DLL4 to modulate endothelial cell behavior during angiogenesis. Blood 120, 5063-5072. doi: 10.1182/blood-201204-423004

Cao, J., Cai, J., Huang, D., Han, Q., Yang, Q., Li, T., et al. (2013). miR-335 represents an invasion suppressor gene in ovarian cancer by targeting Bcl-w. Oncol. Rep. 30, 701-706. doi: 10.3892/or.2013.2482.

Carbillon, L., Challier, J. C., Alouini, S., Uzan, M., and Uzan, S. (2001). Uteroplacental circulation development: Doppler assessment and clinical importance. Placenta 22, 795-799. doi: 10.1053/plac.2001.0732

Carosella, E. D. (2011). The tolerogenic molecule HLA-G. Immunol. Lett. 138, 22-24. doi: 10.1016/j.imlet.2011.02.011

Carter, A. M., and Mess, A. (2007). Evolution of the placenta in eutherian mammals. Placenta 28, 259-262. doi: 10.1016/j.placenta.2006.04.010

Chan, S. Y., Zhang, Y. Y., Hemann, C., Mahoney, C. E., Zweier, J. L., and Loscalzo, J. (2009). MicroRNA-210 controls mitochondrial metabolism during hypoxia by repressing the iron-sulfur cluster assembly proteins ISCU1/2. Cell Metab. 10, 273-284. doi: 10.1016/j.cmet.2009.08.015

Chelbi, S. T., Mondon, F., Jammes, H., Buffat, C., Mignot, T. M., Tost, J., et al. (2007). Expressional and epigenetic alterations of placental serine protease inhibitors: SERPINA3 is a potential marker of preeclampsia. Hypertension 49, 76-83. doi: 10.1161/01.HYP.0000250831.52876.cb

Chelbi, S. T., and Vaiman, D. (2008). Genetic and epigenetic factors contribute to the onset of preeclampsia. Mol. Cell Endocrinol. 282, 120-129. doi: 10.1016/j.mce.2007.11.022

Chelbi, S. T., Wilson, M. L., Veillard, A. C., Ingles, S. A., Zhang, J., Mondon, F., et al. (2012). Genetic and epigenetic mechanisms collaborate to control SERPINA3 expression and its association with placental diseases. Hum. Mol. Genet. 21, 1968-1978. doi: 10.1093/hmg/dds006

Chen, C. P., Chen, C. Y., Yang, Y. C., Su, T. H., and Chen, H. (2004). Decreased placental GCM1 (glial cells missing) gene expression in pre-eclampsia. Placenta 25, 413-421. doi: 10.1016/j.placenta.2003.10.014

Chen, D. B., and Wang, W. (2013). Human placental microRNAs and preeclampsia. Biol. Reprod. 88, 130. doi: 10.1095/biolreprod.113.107805 
Chen, Z., Li, Y., Zhang, H., Huang, P., and Luthra, R. (2010). Hypoxia-regulated microRNA-210 modulates mitochondrial function and decreases ISCU and COX10 expression. Oncogene 29, 4362-4368. doi: 10.1038/onc.2010.193

Chiang, M. H., Liang, F. Y., Chen, C. P., Chang, C. W., Cheong, M. L., Wang, L. J., et al. (2009). Mechanism of hypoxia-induced GCM1 degradation: implications for the pathogenesis of preeclampsia. J. Biol. Chem. 284, 17411-17419. doi: 10.1074/jbc.M109.016170

Cindrova-Davies, T., Herrera, E. A., Niu, Y., Kingdom, J., Giussani, D. A., and Burton, G. J. (2013). Reduced cystathionine gamma-lyase and increased miR-21 expression are associated with increased vascular resistance in growth-restricted pregnancies: hydrogen sulfide as a placental vasodilator. Am. J. Pathol. 182, 14481458. doi: 10.1016/j.ajpath.2013.01.001

Colleoni, F., Padmanabhan, N., Yung, H. W., Watson, E. D., Cetin, I., Tissot van Patot, M. C., et al. (2013). Suppression of mitochondrial electron transport chain function in the hypoxic human placenta: a role for miRNA-210 and protein synthesis inhibition. PLOS ONE 8:e55194. doi: 10.1371/journal.pone. 0055194

Damsky, C. H., and Fisher, S. J. (1998). Trophoblast pseudo-vasculogenesis: faking it with endothelial adhesion receptors. Curr. Opin. Cell Biol. 10, 660-666. doi: 10.1016/S0955-0674(98)80043-4

Deng, C. X., Wynshaw-Boris, A., Shen, M. M., Daugherty, C., Ornitz, D. M. and Leder, P. (1994). Murine FGFR-1 is required for early postimplantation growth and axial organization. Genes Dev. 8, 3045-3057. doi: 10.1101/gad.8. 24.3045

Donker, R. B., Mouillet, J. F., Chu, T., Hubel, C. A., Stolz, D. B., Morelli, A. E., etal. (2012). The expression profile of C19MC microRNAs in primary human trophoblast cells and exosomes. Mol. Hum. Reprod. 18, 417-424. doi: 10.1093/molehr/gas013

Donker, R. B., Mouillet, J. F., Nelson, D. M., and Sadovsky, Y. (2007). The expression of Argonaute 2 and related microRNA biogenesis proteins in normal and hypoxic trophoblasts. Mol. Hum. Reprod. 13, 273-279. doi: 10.1093/molehr/gam006

Doridot, L., Houry, D., Gaillard, H., Chelbi, S. T., Barbaux, S., and Vaiman, D. (2013). miR-34a expression, epigenetic regulation, and function in human placental diseases. Epigenetics doi: 10.4161/epi.26196 [Epub ahead of print].

Drewlo, S., Czikk, M., Baczyk, D., Lye, S., and Kingdom, J. (2011). Glial cell missing-1 mediates over-expression of tissue inhibitor of metalloproteinase4 in severe pre-eclamptic placental villi. Hum. Reprod. 26, 1025-1034. doi: 10.1093/humrep/der053

Enquobahrie, D. A., Abetew, D. F., Sorensen, T. K., Willoughby, D., Chidambaram, K., and Williams, M. A. (2011). Placental microRNA expression in pregnancies complicated by preeclampsia. Am. J. Obstet. Gynecol. 204, 178.e12-178.e21. doi 10.1016/j.ajog.2010.09.004. Epub 2010 Nov 20.

Fish, J. E., Santoro, M. M., Morton, S. U., Yu, S., Yeh, R. F., Wythe, J. D., et al. (2008). miR-126 regulates angiogenic signaling and vascular integrity. Dev. Cell 15, 272-284. doi: 10.1016/j.devcel.2008.07.008

Flor, I., Neumann, A., Freter, C., Helmke, B. M., Langenbuch, M., Rippe, V., et al. (2012). Abundant expression and hemimethylation of C19MC in cell cultures from placenta-derived stromal cells. Biochem. Biophys. Res. Commun. 422, 411416. doi: 10.1016/j.bbrc.2012.05.004

Fornari, F., Milazzo, M., Chieco, P., Negrini, M., Marasco, E., Capranico, G., et al. (2012). In hepatocellular carcinoma miR-519d is up-regulated by $\mathrm{p} 53$ and DNA hypomethylation and targets CDKN1A/p21, PTEN, AKT3 and TIMP2. J. Pathol. 227, 275-285. doi: 10.1002/path.3995

Fu, G., Brkic, J., Hayder, H., and Peng, C. (2013a). MicroRNAs in human placental development and pregnancy complications. Int. J. Mol. Sci. 14, 5519-5544. doi: 10.3390/ijms14035519

Fu, G., Ye, G., Nadeem, L., Ji, L., Manchanda, T., Wang, Y., et al. (2013b). MicroRNA-376c impairs transforming growth factor-beta and nodal signaling to promote trophoblast cell proliferation and invasion. Hypertension 61, 864-872. doi: 10.1161/HYPERTENSIONAHA.111.203489

Gao, W. L., Liu, M., Yang, Y., Yang, H., Liao, Q., Bai, Y., et al. (2012). The imprinted $\mathrm{H} 19$ gene regulates human placental trophoblast cell proliferation via encoding miR-675 that targets nodal modulator 1 (NOMO1). RNA Biol. 9, 1002-1010. doi: 10.4161/rna.20807

Gascoin-Lachambre, G., Buffat, C., Rebourcet, R., Chelbi, S. T., Rigourd, V., Mondon, F., et al. (2010). Cullins in human intra-uterine growth restriction: expressional and epigenetic alterations. Placenta 31, 151-157. doi: 10.1016/j.placenta.2009.11.008
Gasperowicz, M., and Otto, F. (2008). The notch signalling pathway in the development of the mouse placenta. Placenta 29, 651-659. doi: 10.1016/j.placenta.2008.06.004

Geraghty, D. E., Koller, B. H., and Orr, H. T. (1987). A human major histocompatibility complex class I gene that encodes a protein with a shortened cytoplasmic segment. Proc. Natl. Acad. Sci. U.S.A. 84, 9145-9149. doi: 10.1073/pnas.84.24.9145

Girardot, M., Cavaille, J., and Feil, R. (2012). Small regulatory RNAs controlled by genomic imprinting and their contribution to human disease. Epigenetics 7, 1341-1348. doi: 10.4161/epi.22884

Goldman-Wohl, D., and Yagel, S. (2002). Regulation of trophoblast invasion: from normal implantation to pre-eclampsia. Mol. Cell Endocrinol. 187, 233-238. doi: 10.1016/S0303-7207(01)00687-6

Gonzalez, A., Rebmann, V., LeMaoult, J., Horn, P. A., Carosella, E. D., and Alegre, E. (2012). The immunosuppressive molecule HLA-G and its clinical implications. Crit. Rev. Clin. Lab. Sci. 49, 63-84. doi: 10.3109/10408363.2012.677947

Hartmann, D., and Thum, T. (2011). MicroRNAs and vascular (dys)function. Vasc. Pharmacol. 55, 92-105. doi: 10.1016/j.vph.2011.07.005

Hazarika, S., Farber, C. R., Dokun, A. O., Pitsillides, A. N., Wang, T., Lye, R. J., et al. (2013). MicroRNA-93 controls perfusion recovery after hindlimb ischemia by modulating expression of multiple genes in the cell cycle pathway. Circulation 127, 1818-1828. doi: 10.1161/CIRCULATIONAHA.112.000860

Hiby, S. E., Apps, R., Sharkey, A. M., Farrell, L. E., Gardner, L., Mulder, A., et al. (2010). Maternal activating KIRs protect against human reproductive failure mediated by fetal HLA-C2. J. Clin. Invest. 120, 4102-4110. doi: 10.1172/JCI43998

Hiby, S. E., Walker, J. J., O’Shaughnessy K. M., Redman, C. W., Carrington, M., Trowsdale, J., et al. (2004). Combinations of maternal KIR and fetal HLA-C genes influence the risk of preeclampsia and reproductive success. J. Exp. Med. 200, 957-965. doi: 10.1084/jem.20041214

Hsu, P., Santner-Nanan, B., Dahlstrom, J. E., Fadia, M., Chandra, A., Peek, M., et al. (2012). Altered decidual DC-SIGN ${ }^{+}$antigen-presenting cells and impaired regulatory T-cell induction in preeclampsia. Am. J. Pathol. 181, 2149-2160. doi: 10.1016/j.ajpath.2012.08.032

Huang, L., Dai, T., Lin, X., Zhao, X., Chen, X., Wang, C., et al. (2012). MicroRNA224 targets RKIP to control cell invasion and expression of metastasis genes in human breast cancer cells. Biochem. Biophys. Res. Commun. 425, 127-133. doi: 10.1016/j.bbrc.2012.07.025

Huang, X., Ding, L., Bennewith, K. L., Tong, R. T., Welford, S. M., Ang, K. K., et al. (2009). Hypoxia-inducible mir-210 regulates normoxic gene expression involved in tumor initiation. Mol. Cell 35, 856-867. doi: 10.1016/j.molcel.2009.09.006

Hunkapiller, N. M., Gasperowicz, M., Kapidzic, M., Plaks, V., Maltepe, E., Kitajewski, J., et al. (2011). A role for Notch signaling in trophoblast endovascular invasion and in the pathogenesis of pre-eclampsia. Development 138, 2987-2998. doi: 10.1242/dev.066589

Hunt, J. S., Langat, D. K., McIntire, R. H., and Morales, P. J. (2006). The role of HLA-G in human pregnancy. Reprod. Biol. Endocrinol. 4(Suppl. 1), S10. doi: 10.1186/1477-7827-4-S1-S10

Hunt, J. S., Morales, P. J., Pace, J. L., Fazleabas, A. T., and Langat, D. K. (2007). A commentary on gestational programming and functions of HLA-G in pregnancy. Placenta 28(Suppl. A), S57-S63. doi: 10.1016/j.placenta.2007.01.004

Ishibashi, O., Ohkuchi, A., Ali, M. M., Kurashina, R., Luo, S. S., Ishikawa, T., et al. (2012). Hydroxysteroid (17-beta) dehydrogenase 1 is dysregulated by miR-210 and miR-518c that are aberrantly expressed in preeclamptic placentas: a novel marker for predicting preeclampsia. Hypertension 59, 265-273. doi: 10.1161/HYPERTENSIONAHA.111.180232

Jauniaux, E., Gulbis, B., and Burton, G. J. (2003). Physiological implications of the materno-fetal oxygen gradient in human early pregnancy. Reprod. Biomed. Online 7, 250-253. doi: 10.1016/S1472-6483(10)61760-9

Ji, L., Brkic, J., Liu, M., Fu, G., Peng, C., and Wang, Y. (2013). Placental trophoblast cell differentiation: physiological regulation and pathological relevance to preeclampsia. Mol. Aspects Med. 34, 981-1023. doi: 10.1016/j.mam.2012. 12.008

Keniry, A., Oxley, D., Monnier, P., Kyba, M., Dandolo, L., Smits, G., et al. (2012). The H19 lincRNA is a developmental reservoir of miR-675 that suppresses growth and Igf1r. Nat. Cell Biol. 14, 659-665. doi: 10.1038/ncb2521

Kulkarni, S., Savan, R., Qi, Y., Gao, X., Yuki, Y., Bass, S. E., et al. (2011). Differential microRNA regulation of HLA-C expression and its association with HIV control. Nature 472, 495-498. doi: 10.1038/nature09914 
Kulshreshtha, R., Ferracin, M., Wojcik, S. E., Garzon, R., Alder, H., Agosto-Perez, F. J., et al. (2007). A microRNA signature of hypoxia. Mol. Cell Biol. 27, 1859-1867. doi: 10.1128/MCB.01395-06

Kumar, P., Luo, Y., Tudela, C., Alexander, J. M., and Mendelson, C. R. (2013). The c-Myc-regulated MicroRNA-17 92 (miR-17 92) and miR-106a 363 clusters target hCYP19A1 and hGCM1 to inhibit human trophoblast differentiation. Mol. Cell Biol. 33, 1782-1796. doi: 10.1128/MCB.01228-12

Landles, C., Chalk, S., Steel, J. H., Rosewell, I., Spencer-Dene, B., Lalani, el-N., et al. (2003). The thyroid hormone receptor-associated protein TRAP220 is required at distinct embryonic stages in placental, cardiac, and hepatic development. Mol. Endocrinol. 17, 2418-2435. doi: 10.1210/me.2003-0097

Lee, D. C., Romero, R., Kim, J. S., Tarca, A. L., Montenegro, D., Pineles, B. L. et al. (2011). miR-210 targets iron-sulfur cluster scaffold homologue in human trophoblast cell lines: siderosis of interstitial trophoblasts as a novel pathology of preterm preeclampsia and small-for-gestational-age pregnancies. Am. J. Pathol. 179, 590-602. doi: 10.1016/j.ajpath.2011.04.035

Lee, D. W., Futami, M., Carroll, M., Feng, Y., Wang, Z., Fernandez, M., et al. (2012). Loss of SHIP-1 protein expression in high-risk myelodysplastic syndromes is associated with miR-210 and miR-155. Oncogene 31, 4085-4094. doi: 10.1038/onc.2011.579

Li, H. P., Zeng, X. C., Zhang, B., Long, J. T., Zhou, B., Tan, G. S., et al. (2013a). miR-451 inhibits cell proliferation in human hepatocellular carcinoma through direct suppression of IKK-beta. Carcinogenesis doi: 10.1093/carcin/ bgt206

Li, P., Guo, W., Du, L., Zhao, J., Wang, Y., Liu, L., et al. (2013b). microRNA$29 \mathrm{~b}$ contributes to pre-eclampsia through its effects on apoptosis, invasion and angiogenesis of trophoblast cells. Clin. Sci. (Lond.) 124, 27-40. doi: 10.1042/CS20120121

Lin, S., Cheung, W. K., Chen, S., Lu, G., Wang, Z., Xie, D., et al. (2010). Computational identification and characterization of primate-specific microRNAs in human genome. Comput. Biol. Chem. 34, 232-241. doi: 10.1016/j.compbiolchem.2010.08.001

Lou, Y. L., Guo, F., Liu, F., Gao, F. L., Zhang, P. Q., Niu, X., et al. (2012). miR-210 activates notch signaling pathway in angiogenesis induced by cerebral ischemia. Mol. Cell Biochem. 370, 45-51. doi: 10.1007/s11010-012-1396-6

Luo, L., Ye, G., Nadeem, L., Fu, G., Yang, B. B., Honarparvar, E., et al. (2012). MicroRNA-378a-5p promotes trophoblast cell survival, migration and invasion by targeting nodal. J. Cell Sci. 125, 3124-3132. doi: 10.1242/jcs. 096412

Maltepe, E., Bakardjiev, A. I., and Fisher, S. J. (2010). The placenta: transcriptional, epigenetic, and physiological integration during development. J. Clin. Invest. 120 1016-1025. doi: 10.1172/JCI41211

Manaster, I., Goldman-Wohl, D., Greenfield, C., Nachmani, D., Tsukerman, P., Hamani, Y., et al. (2012). MiRNA-mediated control of HLA-G expression and function. PLoS ONE 7:e33395. doi: 10.1371/journal.pone.0033395

Mayor-Lynn, K., Toloubeydokhti, T., Cruz, A. C., and Chegini, N. (2011). Expression profile of microRNAs and mRNAs in human placentas from pregnancies complicated by preeclampsia and preterm labor. Reprod. Sci. 18, 46-56. doi $10.1177 / 1933719110374115$

Medawar, P. B. (1961). Immunological tolerance. Science 133, 303-306. doi 10.1126/science.133.3449.303

Moffett, A., and Loke, C. (2006). Immunology of placentation in eutherian mammals. Nat. Rev. Immunol. 6, 584-594. doi: 10.1038/nri1897

Morales-Prieto, D. M., Chaiwangyen, W., Ospina-Prieto, S., Schneider, U., Herrmann, J., Gruhn, B., et al. (2012). MicroRNA expression profiles of trophoblastic cells. Placenta 33, 725-734. doi: 10.1016/j.placenta.2012.05.009

Morandi, F., and Pistoia, V. (2013). Soluble HLA-G modulates miRNA-210 and miRNA-451 expression in activated $\mathrm{CD}^{+}{ }^{+} \mathrm{T}$ lymphocytes. Int. Immunol. 25 279-285. doi: 10.1093/intimm/dxs108

Mouillet, J. F., Chu, T., Nelson, D. M., Mishima, T., and Sadovsky, Y. (2010). MiR-205 silences MED1 in hypoxic primary human trophoblasts. FASEB J. 24, 2030-2039. doi: 10.1096/fj.09-149724

Mouillet, J. F., Donker, R. B., Mishima, T., Cronqvist, T., Chu, T., and Sadovsky, Y. (2013). The unique expression and function of miR-424 in human placental trophoblasts. Biol. Reprod. 89, 25. doi: 10.1095/biolreprod.113.110049

Munir, S., Xu, G., Wu, Y., Yang, B., Lala, P. K., and Peng, C. (2004). Nodal and ALK7 inhibit proliferation and induce apoptosis in human trophoblast cells. $J$. Biol. Chem. 279, 31277-31286. doi: 10.1074/jbc.M400641200
Muralimanoharan, S., Maloyan, A., Mele, J., Guo, C., Myatt, L. G., and Myatt, L. (2012). MIR-210 modulates mitochondrial respiration in placenta with preeclampsia. Placenta 33, 816-823. doi: 10.1016/j.placenta.2012.07.002

Noguer-Dance, M., Abu-Amero, S., Al-Khtib, M., Lefevre, A., Coullin, P., Moore, G. E., etal. (2010). The primate-specific microRNA gene cluster (C19MC) is imprinted in the placenta. Hum. Mol. Genet. 19, 3566-3582. doi: $10.1093 / \mathrm{hmg} / \mathrm{ddq} 272$

Pang, R. T., Leung, C. O., Ye, T. M., Liu, W., Chiu, P. C., Lam, K. K., et al. (2010). MicroRNA-34a suppresses invasion through downregulation of Notch1 and Jagged 1 in cervical carcinoma and choriocarcinoma cells. Carcinogenesis 31, 1037-1044. doi: 10.1093/carcin/bgq066

Pijnenborg, R., Vercruysse, L., and Hanssens, M. (2006). The uterine spiral arteries in human pregnancy: facts and controversies. Placenta 27, 939-958. doi: 10.1016/j.placenta.2005.12.006

Pineles, B. L., Romero, R., Montenegro, D., Tarca, A. L., Han, Y. M., Kim, Y. M., et al. (2007). Distinct subsets of microRNAs are expressed differentially in the human placentas of patients with preeclampsia. Am. J. Obstet. Gynecol. 196, 261.e1-261.e6.

Poliseno, L., Tuccoli, A., Mariani, L., Evangelista, M., Citti, L., Woods, K., et al. (2006). MicroRNAs modulate the angiogenic properties of HUVECs. Blood 108, 3068-3071. doi: 10.1182/blood-2006-01-012369

Red-Horse, K., Kapidzic, M., Zhou, Y., Feng, K. T., Singh, H., and Fisher, S. J. (2005). EPHB4 regulates chemokine-evoked trophoblast responses: a mechanism for incorporating the human placenta into the maternal circulation. Development 132, 4097-4106. doi: 10.1242/dev.01971

Red-Horse, K., Zhou, Y., Genbacev, O., Prakobphol, A., Foulk, R., McMaster, M., et al. (2004). Trophoblast differentiation during embryo implantation and formation of the maternal-fetal interface. J. Clin. Invest. 114, 744-754.

Renfree, M. B., Suzuki, S., and Kaneko-Ishino, T. (2013). The origin and evolution of genomic imprinting and viviparity in mammals. Philos. Trans. R. Soc. Lond. B Biol. Sci. 368, 20120151. doi: 10.1098/rstb.2012.0151

Rigourd, V., Chauvet, C., Chelbi, S. T., Rebourcet, R., Mondon, F., Letourneur, F., et al. (2008). STOX1 overexpression in choriocarcinoma cells mimics transcriptional alterations observed in preeclamptic placentas. PLOS ONE 3:e3905. doi: 10.1371/journal.pone.0003905

Rigourd, V., Chelbi, S., Chauvet, C., Rebourcet, R., Barbaux, S., Bessieres, B. et al. (2009) Re-evaluation of the role of STOX1 transcription factor in placental development and preeclampsia. J. Reprod. Immunol. 82, 174-181. doi: 10.1016/j.jri.2009.05.001

Roca, C., and Adams, R. H. (2007). Regulation of vascular morphogenesis by Notch signaling. Genes Dev. 21, 2511-2524. doi: 10.1101/gad.1589207

Samstein, R. M., Josefowicz, S. Z., Arvey, A., Treuting, P. M., and Rudensky, A. Y. (2012). Extrathymic generation of regulatory T cells in placental mammals mitigates maternal-fetal conflict. Cell 150, 29-38. doi: 10.1016/j.cell.2012. 05.031

Santner-Nanan, B., Peek, M. J., Khanam, R., Richarts, L., Zhu, E., Fazekas de St Groth, B., et al. (2009). Systemic increase in the ratio between Foxp3 ${ }^{+}$and IL17 -producing $\mathrm{CD}^{+} \mathrm{T}$ cells in healthy pregnancy but not in preeclampsia. $J$. Immunol. 183, 7023-7030. doi: 10.4049/jimmunol.0901154

Sawamiphak, S., Seidel, S., Essmann, C. L., Wilkinson, G. A., Pitulescu, M. E., Acker, T., et al. (2010). Ephrin-B2 regulates VEGFR2 function in developmental and tumour angiogenesis. Nature 465, 487-491. doi: 10.1038/nature08995

Sekita, Y., Wagatsuma, H., Nakamura, K., Ono, R., Kagami, M., Wakisaka, N., et al. (2008). Role of retrotransposon-derived imprinted gene, Rtll, in the feto-maternal interface of mouse placenta. Nat. Genet. 40, 243-248. doi: 10.1038/ng.2007.51

Sibai, B. M. (2005). Thrombophilia and severe preeclampsia: time to screen and treat in future pregnancies? Hypertension 46, 1252-1253. doi: 10.1161/01.HYP.0000188904.47575.7e

Small, E. M., and Olson, E. N. (2011). Pervasive roles of microRNAs in cardiovascular biology. Nature 469, 336-342. doi: 10.1038/nature09783

Suarez, Y., Fernandez-Hernando, C., Yu, J., Gerber, S. A., Harrison, K. D., Pober, J. S., et al. (2008). Dicer-dependent endothelial microRNAs are necessary for postnatal angiogenesis. Proc. Natl. Acad. Sci. U.S.A. 105, 14082-14087. doi: 10.1073/pnas.0804597105

Swift, M. R., and Weinstein, B. M. (2009). Arterial-venous specification during development. Circ. Res. 104, 576-588. doi: 10.1161/CIRCRESAHA.108. 188805 
Tan, Z., Randall, G., Fan, J., Camoretti-Mercado, B., Brockman-Schneider, R., Pan, L., et al. (2007). Allele-specific targeting of microRNAs to HLA-G and risk of asthma. Am. J. Hum. Genet. 81, 829-834. doi: 10.1086/521200

Turner, C. L., Mackay, D. M., Callaway, J. L., Docherty, L. E., Poole, R. L., Bullman, H., et al. (2010). Methylation analysis of 79 patients with growth restriction reveals novel patterns of methylation change at imprinted loci. Eur. J. Hum. Genet. 18, 648-655. doi: 10.1038/ejhg.2009.246

Vaiman, D., Calicchio, R., and Miralles, F. (2013). Landscape of transcriptional deregulations in the preeclamptic placenta. PLoS ONE 8:e65498. doi: 10.1371/journal.pone.0065498

Varrault, A., Gueydan, C., Delalbre, A., Bellmann, A., Houssami, S., Aknin, C., et al (2006). Zacl regulates an imprinted gene network critically involved in the contro of embryonic growth. Dev. Cell 11, 711-722. doi: 10.1016/j.devcel.2006.09.003

Wang, H., Li, M., Zhang, R., Wang, Y., Zang, W., Ma, Y., et al. (2013a). Effect of miR-335 upregulation on the apoptosis and invasion of lung cancer cell A549 and H1299. Tumour Biol. 34, 3101-3109. doi: 10.1007/s13277-013-0878-9

Wang, K., Ahmad, S., Cai, M., Rennie, J., Fujisawa, T., Crispi, F., et al. (2013b). Dysregulation of hydrogen sulfide producing enzyme cystathionine gamma-lyase contributes to maternal hypertension and placental abnormalities in preeclampsia. Circulation 127, 2514-2522. doi: 10.1161/CIRCULATIONAHA.113.001631

Wang, H. U., Chen, Z. F., and Anderson, D. J. (1998). Molecular distinction and angiogenic interaction between embryonic arteries and veins revealed by ephrinB2 and its receptor Eph-B4. Cell 93, 741-753. doi: 10.1016/S0092-8674(00) 81436-1

Wang, S., Aurora, A. B., Johnson, B. A., Qi, X., McAnally, J., Hill, J. A., et al. (2008). The endothelial-specific microRNA miR-126 governs vascular integrity and angiogenesis. Dev. Cell 15, 261-271. doi: 10.1016/j.devcel.2008.07.002

Wang, W., Feng, L., Zhang, H., Hachy, S., Satohisa, S., Laurent, L. C., et al. (2012). Preeclampsia up-regulates angiogenesis-associated microRNA (i.e., miR17, -20a, and -20b) that target ephrin-B2 and EPHB4 in human placenta. J. Clin. Endocrinol. Metab. 97, E1051-E1059. doi: 10.1210/jc.2011-3131

Wang, Z. G., Puri, T. S., and Quigg, R. J. (2010). Characterization of novel VEGF (vascular endothelial growth factor)-C splicing isoforms from mouse. Biochem. J. 428, 347-354. doi: 10.1042/BJ20100379

Wiendl, H., Feger, U., Mittelbronn, M., Jack, C., Schreiner, B., Stadelmann, C., et al. (2005). Expression of the immune-tolerogenic major histocompatibility molecule HLA-G in multiple sclerosis: implications for CNS immunity. Brain 128, 2689-2704. doi: 10.1093/brain/awh609

Wilson, M. L., Brueggmann, D., Desmond, D. H., Mandeville, J. E., Goodwin, T. M., and Ingles, S. A. (2011). A fetal variant in the GCM1 gene is associated with pregnancy induced hypertension in a predominantly hispanic population. Int. J. Mol. Epidemiol. Genet. 2, 196-206.

Xu, X., Sarikas, A., Dias-Santagata, D. C., Dolios, G., Lafontant, P. J., Tsai, S. C., et al. (2008). The CUL7 E3 ubiquitin ligase targets insulin receptor substrate 1 for ubiquitin-dependent degradation. Mol. Cell 30, 403-414. doi: 10.1016/j.molcel.2008.03.009
Yamaguchi, T. P., Harpal, K., Henkemeyer, M., and Rossant, J. (1994). fgfr-1 is required for embryonic growth and mesodermal patterning during mouse gastrulation. Genes Dev. 8, 3032-3044. doi: 10.1101/gad.8.24.3032

Yan, T., Liu, Y., Cui, K., Hu, B., Wang, F., and Zou, L. (2013). MiR-126 regulates EPCs function: implications for a role of miR-126 in preeclampsia. J. Cell Biochem. 114, 2148-2159. doi: 10.1002/jcb.24563

Yang, G., Pei, Y., Cao, Q., and Wang, R. (2012). MicroRNA-21 represses human cystathionine gamma-lyase expression by targeting at specificity protein1 in smooth muscle cells. J. Cell Physiol. 227, 3192-3200. doi: 10.1002/jcp. 24006

Yang, W. J., Yang, D. D., Na, S., Sandusky, G. E., Zhang, Q., and Zhao, G. (2005). Dicer is required for embryonic angiogenesis during mouse development. J. Biol. Chem. 280, 9330-9335. doi: 10.1074/jbc.M413394200

Yoshimizu, T., Miroglio, A., Ripoche, M. A., Gabory, A., Vernucci, M., Riccio, A., et al. (2008). The H19 locus acts in vivo as a tumor suppressor. Proc. Natl. Acad. Sci. U.S.A. 105, 12417-12422. doi: 10.1073/pnas. 0801540105

Yu, L. L., Chang, K., Lu, L. S., Zhao, D., Han, J., Zheng, Y. R., et al. (2013). Lentivirusmediated RNA interference targeting the $\mathrm{H} 19$ gene inhibits cell proliferation and apoptosis in human choriocarcinoma cell line JAR. BMC Cell Biol. 14:26. doi: 10.1186/1471-2121-14-26

Zhang, Y., Fei, M., Xue, G., Zhou, Q., Jia, Y., Li, L., et al. (2012). Elevated levels of hypoxia-inducible microRNA-210 in pre-eclampsia: new insights into molecular mechanisms for the disease. J. Cell Mol. Med. 16, 249-259. doi: 10.1111/j.15824934.2011.01291.x

Zhou, Y., Fisher, S. J., Janatpour, M., Genbacev, O., Dejana, E., Wheelock, M., et al. (1997). Human cytotrophoblasts adopt a vascular phenotype as they differentiate. A strategy for successful endovascular invasion? J. Clin. Invest. 99, 2139-2151. doi: 10.1172/JCI119387

Conflict of Interest Statement: The authors declare that the research was conducted in the absence of any commercial or financial relationships that could be construed as a potential conflict of interest.

Received: 11 July 2013; accepted: 30 October 2013; published online: 21 November 2013.

Citation: Doridot L, Miralles F, Barbaux S and Vaiman D (2013) Trophoblasts, invasion, and microRNA. Front. Genet. 4:248. doi: 10.3389/fgene.2013.00248

This article was submitted to Epigenomics and Epigenetics, a section of the journal Frontiers in Genetics.

Copyright (C) 2013 Doridot, Miralles, Barbaux and Vaiman. This is an open-access article distributed under the terms of the Creative Commons Attribution License (CC BY). The use, distribution or reproduction in other forums is permitted, provided the original author(s) or licensor are credited and that the original publication in this journal is cited, in accordance with accepted academic practice. No use, distribution or reproduction is permitted which does not comply with these terms. 